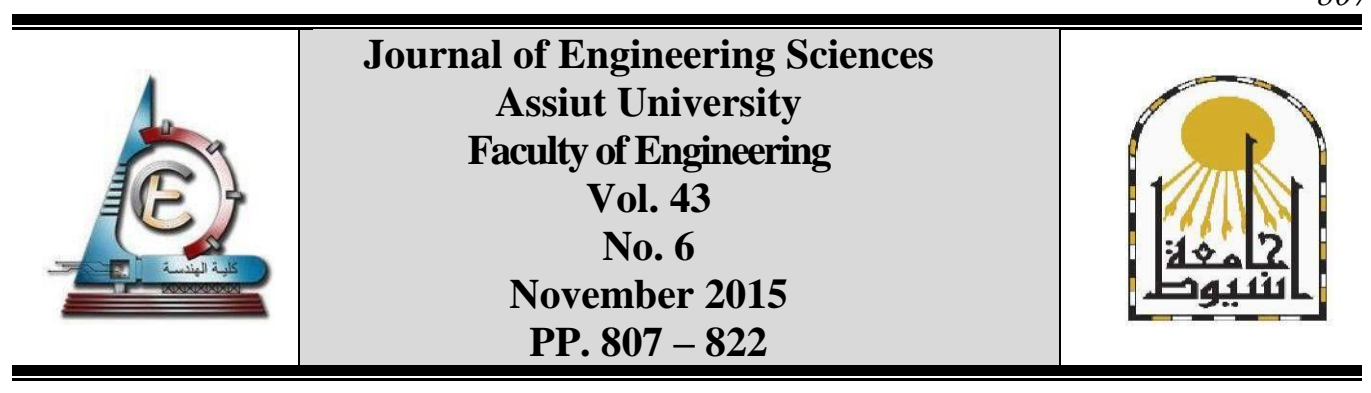

\title{
EFFECT OF INLET AND OUTLET GEOMETRIC SHAPE VARIATIONS OF A PIPE CULVERT ON LOCAL HEAD-LOSSES
}

\author{
Nassralla T. H. \\ Civil Eng Department, Benha University, Egypt.
}

(Received 12 August 2015; Accepted 21 September 2015)

\begin{abstract}
This research investigates the losses resulting from the sudden contraction and expansion of a pipe culvert. A four hundred runs were carried out considering various angles and contraction ratios at inlet and outlet of the pipe culvert and downstream submerged ratios with different flow conditions. Results were analyzed and graphically presented. The results indicated that the inlet angle of $15^{\circ}$ with width contraction ratio of $\left(b_{u} / D=2.33\right)$ gives the least values of losses at the transition from a free-surface channel to the pipe culvert. For the transition from a conduit to a free-surface channel, the outlet angle of $60^{\circ}$ with a submerged ratio of $\left(\mathrm{h}_{\mathrm{d}} / \mathrm{D}=0.20\right)$ and the outlet angle of $30^{\circ}$ with submerged ratios of $\left(h_{d} / D=0.4,0.6\right.$ and 0.8$)$ give the least values of losses at width contraction ratio of $\left(b_{d} / D=2.33\right)$. These results agree well with the results obtained from previous studies.
\end{abstract}

Keywords: Culvert; Energy Loss; Pipe Entrance; Pipe Exit; Physical Model.

\section{Introduction}

The culvert consists of three main parts, namely the inlet, barrel and outlet. Flows in the culvert may be pressurized flow or open channel flows. Its cross section may be circular or box in shape. The different types of flow through the culvert have been previously described by Bodhaine [4], Chow [1], Blasidell [2], Dasika [6], Montes, [7], Hager and Giudice [9], Meselhe and Hebert [11] and Nguyen et al. [15].

In hydraulics, two kinds of energy losses may be take place, [12]. The first kind is due to shear stresses along the boundary walls, and is designated as friction loss due to surface resistance and the second one is intimately linked with the variations in the flow-path geometry, resulting in local-flow transitional. The local losses are known to be proportional to the dynamic pressure or kinetic energy of the flow. Usual formulations to compute a local head-loss coefficient from conduct velocity head is related to the flow velocity downstream of the conduit expansion/contraction, Gardel [3] and Idel'cik [5]. Idel'cik [5] considered wide spectra of geometry variations and varied circular conduit inlet configurations from a reservoir with negligible flow velocity. He [5] also proposed local head-loss coefficients for square conduit inlet protruding in a reservoir, depending on the conduit location and sidewall thickness. He [5] found the head-loss coefficient is equal to 0.63 when the conduit bottom is aligned with the reservoir bottom. When a sidewall and 
the bottom of the conduit are those of the reservoir, the head-loss coefficient is equal to 0.77 . Each conduit had a wall thickness that equals $0.03-0.04$ times the width of the square conduit. Hager [12] summarized several local head-loss coefficient expressions for a conduit expansion/contraction. Hager [12] and Gardel [3] developed a head-loss coefficient formula for a conduit contraction when the wall angle of the contraction is equal to $90^{\circ}$. Norman et al. [10] provided detailed information about the hydraulic design method of highway culverts, considering varied geometries of the inlet. This design method was published in a report entitled Hydraulic Design of Highway Culverts. Gisonni and Pfister [17] investigated experimentally the flow features of combining flows at $45^{\circ}$ and $90^{\circ}$ junction manholes on circular conduits, with various diameters. They applied energy and momentum conservation along with their experimental results to provide expressions for the head loss coefficients. Tullis et al. [13] experimentally determined the entrance-loss coefficients for circular/elliptical buried-invert culverts in both unsubmerged and submerged culvert inlet conditions. These experiments have been carried out for circular culverts with invert burial depths of $20 \%, 40 \%$, and $50 \%$ and an elliptical culvert with $50 \%$ invert burial depth. The obtained coefficients varied depending on the geometry and the culvert inlet end treatments.

The present study aims to investigate the local head losses using different geometries of the sidewall at the inlet and outlet of the culvert (upstream/downstream sidewall thickness, angles) and downstream submergence ratios with different flow conditions.

\section{Theoretical approach}

The energy loss at the transition section from an open channel to a pipe culvert at upstream side of the culvert, $\Delta \mathrm{E}_{\mathrm{T} 1}$, and the energy loss at the transition section from a conduit to an open channel at downstream side of the pipe culvert, $\Delta \mathrm{E}_{\mathrm{T} 2}$ depend on a large number of flow variables as follows:

$$
\begin{aligned}
\Delta \mathrm{E}_{\mathrm{T} 1} & =f\left(A, B, b_{u}, D, g, h_{d}, h_{i}, L, L_{u}, p_{i}, S, V_{i}, \rho, \theta_{1}, \mu\right) \\
\Delta \mathrm{E}_{\mathrm{T} 2} & =f\left(A, B, b_{d}, D, g, h_{d}, h_{i}, L, L_{d}, p_{i}, S, V_{i}, \rho, \theta_{2}, \mu\right)
\end{aligned}
$$

Where, $A$ is wetted area of cross section, $B$ is upstream and downstream open channel width, $b_{u}$ or $b_{d}=\left(B-2 b_{w}\right)$ is width of the contracted section at upstream or downstream, $b_{w}$ is width of upstream or downstream sidewall, $D$ is the diameter of the pipe culvert, $g$ is gravitational acceleration, $h_{d}$ is submergence of the pipe culvert at downstream sides of the culvert, $h_{i}$ is water depth at cross section i of the free-surface channel, $L$ is pipe culvert length, $L_{u}$ and $L_{d}$ are lengths of the sidewalls at upstream and downstream sides of the culvert, $p_{i}$ is pressure at cross section i of the conduit, $S$ is bed slope in the free-surface channel/conduit reach, $V_{i}$ is mean flow velocity at cross section i, $\theta_{1}$ and $\theta_{2}$ are inlet and outlet angles of the sidewalls, $\rho$ is density of the water and $\mu$ is dynamic viscosity of water, see Fig 1 .

Since $\rho, \mu, D, B, L, L_{u}$ and $L_{d}$ were kept constant throughout the experimental program. The various parameters affecting the local head loss that taking place at the transition from a rectangular free-surface channel to a pipe conduit or vice-versa may be written as follows:

$$
\left(\frac{\Delta E_{T 1}}{D} \operatorname{or} \frac{\Delta E_{T 2}}{D}=f\left(F_{r}=\frac{V}{\sqrt{g D}}, R_{e}=\frac{\rho V D}{\mu}, \frac{b_{u}}{D}, \frac{b_{d}}{D}, \frac{h_{d}}{D}, \theta_{1}, \theta_{2}\right)\right)
$$


Nassralla, T. H., Effect of inlet and outlet geometric shape variations of a pipe culvert on .........

The values of Reynolds number in this study are beyond $10^{4}$, so, it is not incorporated. Montes [8] reported that for Reynolds numbers higher than $10^{4}$, the viscous effects become less important.
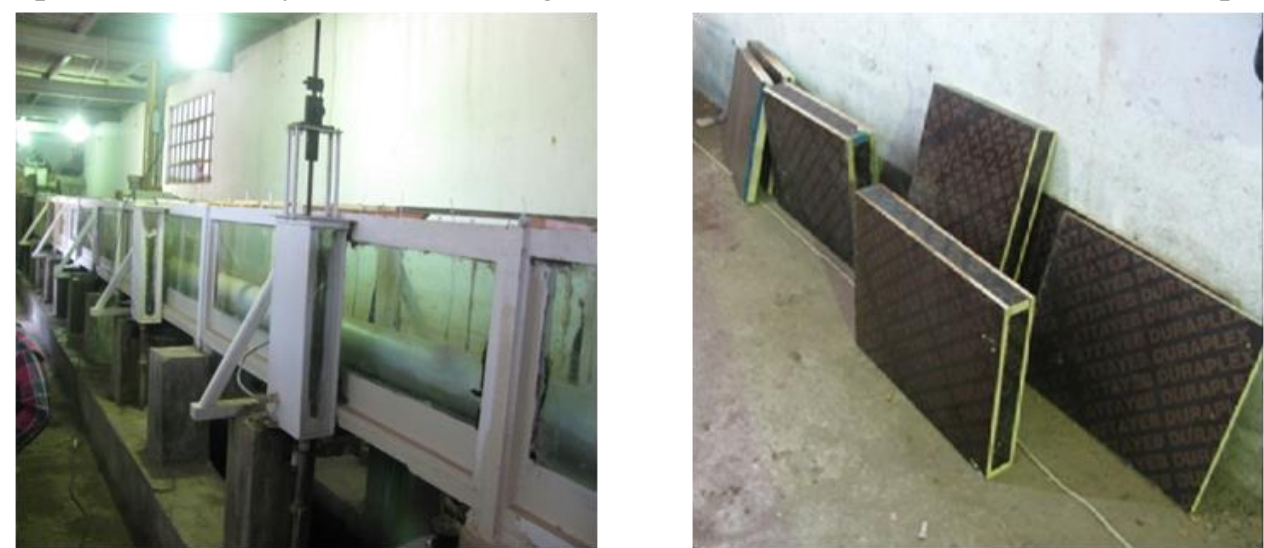

Fig. 1. General view of used flume and considered (sidewalls)

\section{Experiments}

The experiments were conducted in a $40 \mathrm{~m}$ long, $0.40 \mathrm{~m}$ wide and $0.60 \mathrm{~m}$ deep glass flume, see Fig. 1. The experiments were carried out at the hydraulics Research Institute of National Water Research Center. All the tested configurations consider a $6 \mathrm{~m}$ long one PVC pipe between two free-surface-flow channels, $5 \mathrm{~m}$ long upstream and downstream, respectively. The culvert bed level is constant along the system with the flume bed. The channel and the pipe culvert had the same axis in plan. The inner diameter of the pipe $\mathrm{D}=$ $0.15 \mathrm{~m}$. The upstream and downstream sidewalls with a length of $0.4 \mathrm{~m}$ were made in a rectangular cross section with a width, $b_{w}$ of $(2.5,5,7.5,10$, and $12.5 \mathrm{~cm})$ depending on the configuration. Steady discharges of $(4,7,10,12$, and $15 \mathrm{~L} / \mathrm{s})$ were flowing upstream of the flume through a permeable screen ensuring uniform velocity distribution over the cross section. In the downstream, a tailgate is used to control the water level in the flume, depending on the downstream submergence of the culvert.

Four hundred runs were carried out considering aforementioned five discharges, for each discharge four submergence ratios of $\left(h_{d} / D=0.2,0.4,0.6\right.$, and 0.8$)$ were used. For each submergence ratio and at a constant downstream contraction ratio of $\left(b_{d} / D=1.67\right)$, Norman et al. [10], the upstream contraction ratios are changed six times $\left(b_{u} / D=2.33\right.$, $2.00,1.67,1.33$, and 1.00) to reach the best upstream contraction ratio. The best upstream contraction ratio is used and then the downstream contraction ratios are changed six times $\left(b_{d} / D=2.33,2.00,1.67,1.33\right.$, and 1.00) to reach the best downstream contraction ratio. With a constant angle of $90^{\circ}$ at downstream sidewalls, the angle of the upstream sidewalls is changed five times $\left(\theta_{1}=15,30,45,60\right.$, and $\left.90^{\circ}\right)$ to reach the best inlet angle. The optimum upstream angle $\left(15^{\circ}\right)$ is used and then the angle of the downstream sidewalls is changed five times $\left(\theta_{2}=15,30,45,60\right.$, and $\left.90^{\circ}\right)$. In this study, the upstream water depth $\mathrm{h}_{1}$ varies depending on the discharge $\mathrm{Q}$ and downstream submergence. Specific cross sections have been selected to compute the flow energy upstream and downstream of the transition. The location of these sections is shown in Fig. 2. Sections 1, 3, and 5 are far enough from the transition to ensure uniform flow-velocity conditions and thus to be used to compute the flow energy from water depth and pressure measurements, respectively, in the freesurface channel and in the pipe culvert. The difference in energy values between sections 1 
810

JES, Assiut University, Faculty of Engineering, Vol. 43, No. 6, November 2015, pp. 807 - 822

and 3 and sections 3 and 5 provide the local head loss. Energy in sections 1, 3, and 5 is computed from the measurements in sections 1, 3 and 5 considering friction losses between the measurements in sections 1 and 3, 3 and 5. Each test has been repeated three times to ensure the consistency of the results.

The flume has been equipped with electromagnetic flow-meter to measure the discharge (flow rate). The water levels were measured in free surface channels by two precise digital point gauges. They mounted on carriage moving in the flow and the perpendicular directions in addition to four ultrasound sensors placed in Sections 1, 2, 4, and 5 in Fig. 2 with an accuracy of $\pm 0.5 \mathrm{~mm}$. The pressure in closed conduct pipe was measured by a piezoresistive pressure transducers placed in section 3, see Fig. 2.

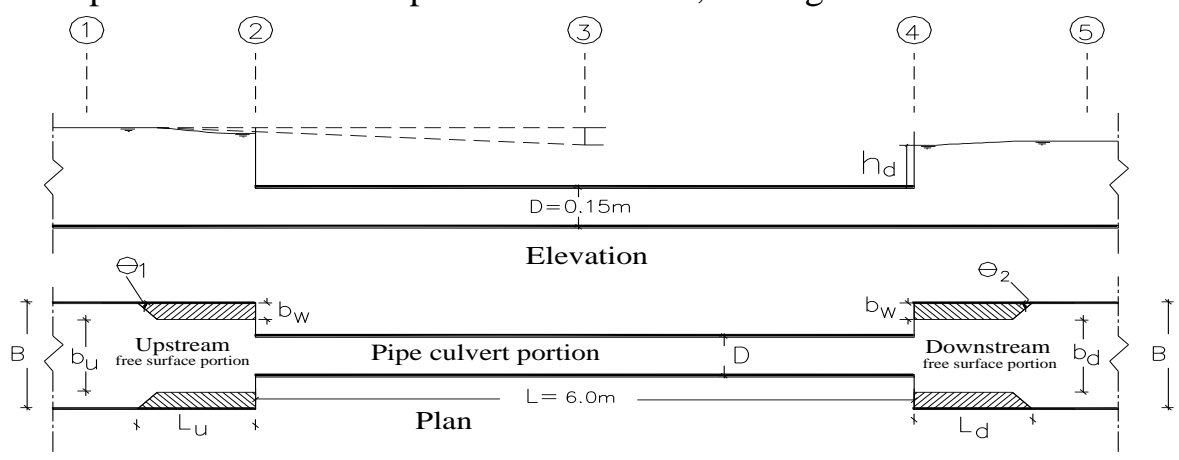

Fig. 2. Layout of geometric configuration and measurement cross sections

\section{Results and discussions}

The flow depths upstream and downstream of the pipe culvert were measured and the mean flow velocity is computed as follows:

$$
V_{i}=\frac{Q}{b_{i} h_{i}}
$$

And at the closed conduit portion, the mean flow velocity is computed as follows:

$$
V_{3}=\frac{Q}{\pi D^{2} / 4}
$$

The mean flow energy E are computed in open cross sections and at section 3 (with an elevation reference at the channel bottom) as follows:

$$
\begin{aligned}
& E_{i}=h_{i}+\frac{V_{i}^{2}}{2 g} \\
& E_{3}=\frac{p_{3}}{\gamma}+\frac{V_{3}^{2}}{2 g}
\end{aligned}
$$

In which $\mathrm{p}_{3} / \gamma$ is pressure head at cross section 3 of the pipe culvert. The energy losses at the entrance $\Delta \mathrm{E}_{\mathrm{T} 1}$ and at the exit $\Delta \mathrm{E}_{\mathrm{T} 2}$ are as computed as:

$$
\begin{aligned}
& \Delta E_{T 1}=\Delta E_{1-3}-\Delta E_{1-2}-\Delta E_{2-3} \\
& \Delta E_{T 2}=\Delta E_{3-5}-\Delta E_{3-4}-\Delta E_{4-5}
\end{aligned}
$$


Nassralla, T. H., Effect of inlet and outlet geometric shape variations of a pipe culvert on ..........

Where $\Delta E_{1-3}$ and $\Delta E_{3-5}$ are energy difference from section 1 to 3 , and from section 3 to 5 .

$\Delta E_{1-2}, \Delta E_{2-3}, \Delta E_{3-4}$ and $\Delta E_{4-5}$ are friction losses between these sections. The friction losses may be estimated using Darcy- Weisbach formula, Eq. 9 as follows:

$$
\Delta E_{j}=\frac{f_{j} x_{j}}{D_{h, j}} \frac{V_{j}^{2}}{2 g}
$$

Where the subscript $\mathrm{j}$ represents free-surface channel reaches or the conduit reaches, $\mathrm{x}$ is reach length; $\mathrm{V}$ and $\mathrm{D}_{\mathrm{h}}$ are flow velocity and hydraulic diameter, respectively, $\mathrm{f}$ is friction factor and is equal to 0.016 for the free-surface channel, 0.004 for the pipe culvert reach. For the considered wall materials, these values are obtained from the results presented by McGovern [14].

\subsection{Effect of upstream contraction ratio $\left(b_{u} / D\right)$ on Local Head-Loss $\left(\Delta E_{T 1}\right)$}

Results were grouped into dimensionless terms and the relationships were drawn to study the effect of the upstream contracted widths (Contraction ratios $b_{u} / D$ ) on relative values of the local head-loss $\Delta \mathrm{E}_{\mathrm{T} 1} / \mathrm{D}$ at the transition from a free open channel to a pipe culvert and were presented graphically in Figs.(from 3 to 6 ) as a function of the tested Froude number, $F_{r}$. for different values of downstream submergence ratio $\left(h_{d} / D\right)$, $\left(\theta_{1}=\theta_{2}=90^{\circ}\right)$, and downstream contraction ration $\left(b_{d} / D=1.67\right)$

For all considered downstream submergence ratios $h_{d} / D$ with all tested values of $F_{r}$, the value of $\mathrm{b}_{\mathrm{u}} / \mathrm{D}=2.33$ gives the lower values of $\Delta \mathrm{E}_{\mathrm{T} 1} / \mathrm{D}$, meaning that, increasing the value of $b_{u} / D$ decreases the value of $\Delta \mathrm{E}_{\mathrm{T}_{1}} / \mathrm{D}$. Also, for all considered values of upstream contraction ratios $b_{u} / D$ with all tested values of $h_{d} / D$, it is clear that $\Delta \mathrm{E}_{T 1} / D$ is increased as $F_{r}$ increases. For lower values of $F_{r}$, all used values of $b_{u} / D$ had small influence on the values of $\Delta \mathrm{E}_{\mathrm{T} 1} / \mathrm{D}$. Finally, by comparing these figures, it is easy to observe that, the value of downstream submergence ratio $h_{d} / D$ had small effect on the values of $\Delta E_{T 1} / D$ for all considered values of $b_{u} / D$ with all tested values of $F_{r}$. Generally, for all considered values of submergence ratio $\left(h_{d} / D\right)$ with all tested values of $F_{r}$, using the smallest value of upstream contraction $\left(b_{u} / D=2.33\right)$ gives the minimum values of the local head-loss $\Delta \mathrm{E}_{T 1}$ at the transition from free flow to pipe flow.

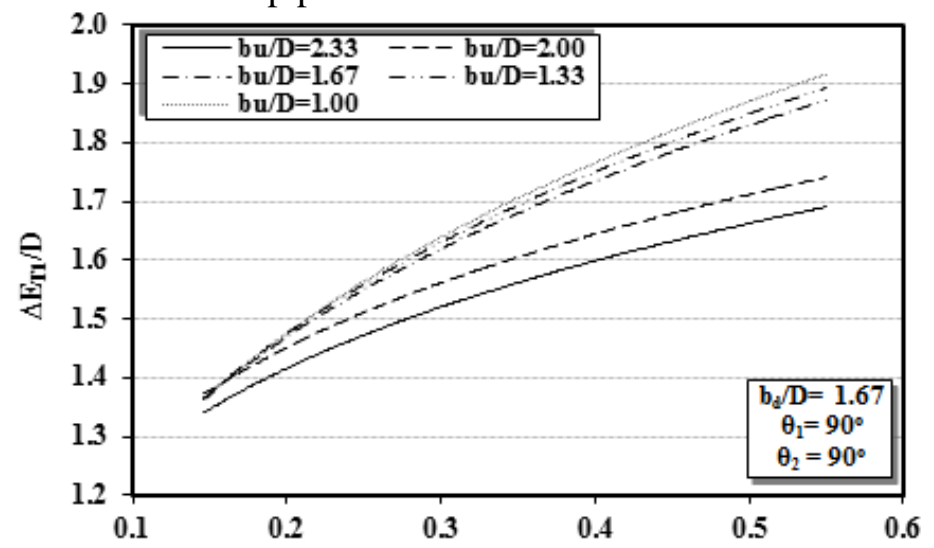

Fig. 3. Relation between $\Delta E_{T 1} / D$ and $F_{r}$ for ${ }^{F_{r}}$ different values of $b_{u} / D$ at $h_{d} / D=0.2$ 


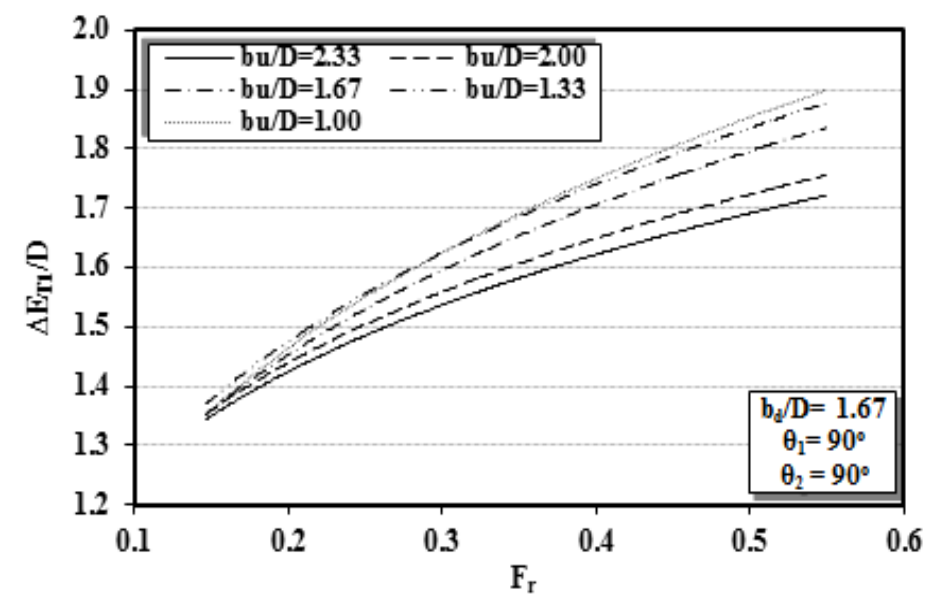

Fig. 4. Relation between $\Delta \mathrm{E}_{\mathrm{T} 1} / \mathrm{D}$ and $\mathrm{F}_{\mathrm{r}}$ for different values of $\mathrm{b}_{\mathrm{u}} / \mathrm{D}$ at $\mathrm{h}_{\mathrm{d}} / \mathrm{D}=0.4$

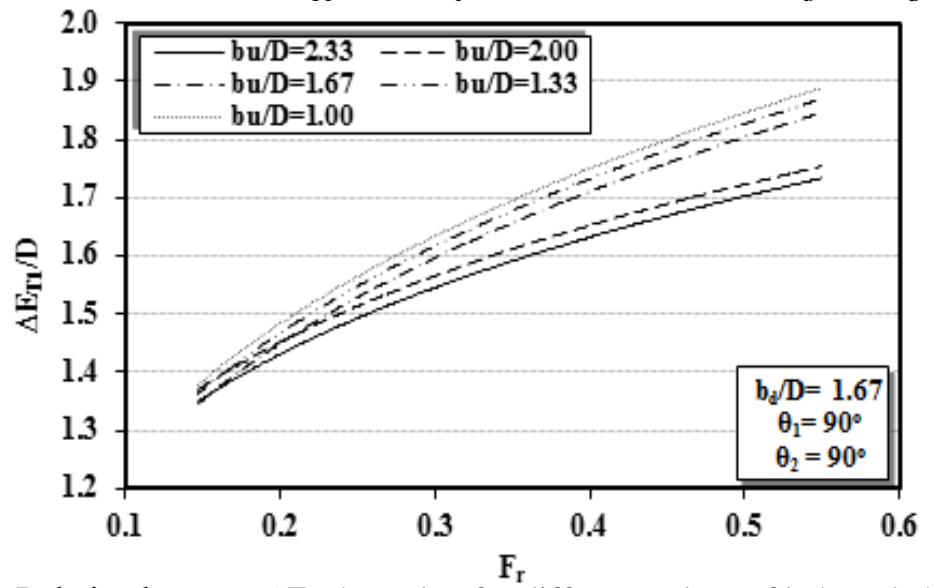

Fig. 5. Relation between $\Delta \mathrm{E}_{\mathrm{Tl}} / \mathrm{D}$ and $\mathrm{F}_{\mathrm{r}}$ for different values of $\mathrm{b}_{\mathrm{u}} / \mathrm{D}$ at $\mathrm{h}_{\mathrm{d}} / \mathrm{D}=0.6$

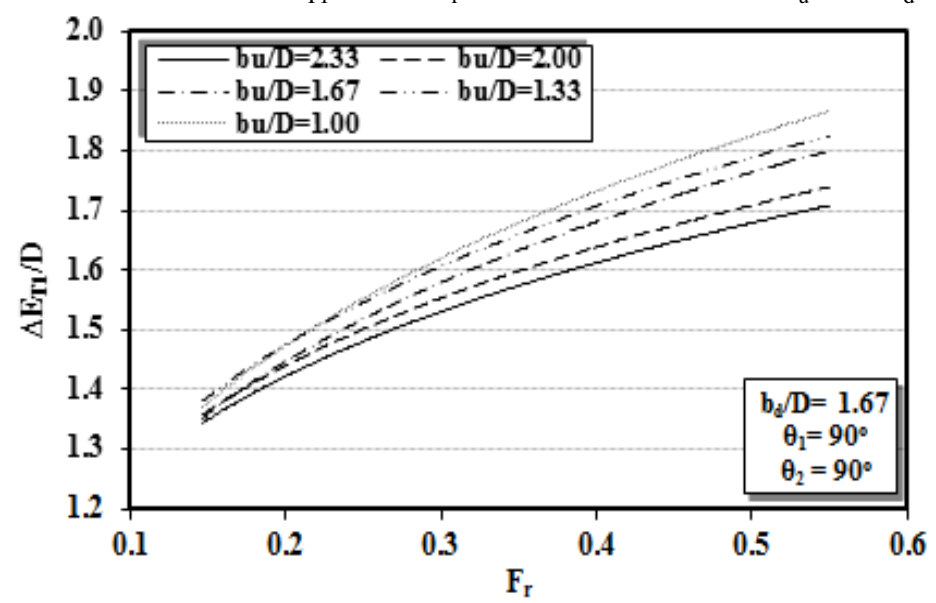

Fig. 6. Relation between $\Delta \mathrm{E}_{\mathrm{T} 1} / \mathrm{D}$ and $\mathrm{F}_{\mathrm{r}}$ for different values of $\mathrm{b}_{\mathrm{u}} / \mathrm{D}$ at $\mathrm{h}_{\mathrm{d}} / \mathrm{D}=0.8$

\subsection{Effect of upstream angle of sidewall $\left(\theta_{1}\right)$ on Local Head-Loss $\left(\Delta E_{T 1}\right)$}

The relationships were graphically presented to study the effect of the inlet angle of the upstream sidewalls $\theta_{1}$ on relative values of the local head-loss $\Delta \mathrm{E}_{\mathrm{T} 1} / \mathrm{D}$ at the transition from free flow to pipe flow as shown in Figs. (from 7 to 10) as a function of the tested 
Nassralla, T. H., Effect of inlet and outlet geometric shape variations of a pipe culvert on ..........

Froude number, $\mathrm{F}_{\mathrm{r}}$. for different values of $\left(\mathrm{h}_{\mathrm{d}} / \mathrm{D}\right)$ and, $\theta_{1}$ was taken as a third dimension. $\theta_{2}$ was kept constant at $90^{\circ}$ and also $b_{u} / D$ and $b_{d} / D$ equal to 2.33 .

For all considered downstream submergence ratios $h_{d} / D$ with all tested values of $F_{r}$, the value of $\theta_{1}=15^{\circ}$ gives the smaller values of $\Delta \mathrm{E}_{\mathrm{T} 1} / \mathrm{D}$ and the value of $\theta_{1}=90^{\circ}$ gives the higher values of $\Delta \mathrm{E}_{\mathrm{T} 1} / \mathrm{D}$, meaning that, decreasing the value of $\theta_{1}$ decreases the value of $\Delta \mathrm{E}_{\mathrm{T} 1} / \mathrm{D}$. This result agrees well with the results obtained by Awad M. [16].

For all considered values of the inlet angle $\theta_{1}$ with all tested values of $h_{d} / D$, it is clear that $\Delta \mathrm{E}_{\mathrm{T} 1} / \mathrm{D}$ is increased as $\mathrm{F}_{\mathrm{r}}$ increases. By comparing these results, it is easy to observe that for all considered values of $\theta_{1}$ with all tested values of $F_{r}$, the value of downstream submergence ratio $h_{d} / D$ had small effect on the values of $\Delta E_{T 1} / D$. Finally, for lower values of $F_{r}$, all tested values of $\theta_{1}$ had small influence on the values of $\Delta \mathrm{E}_{\mathrm{T} 1} / \mathrm{D}$. Generally, for all considered values of submergence ratio $\left(h_{d} / D\right)$ with all tested values of $F_{r}$, using the smallest value of inlet angle of the upstream sidewall $\left(\theta_{1}=15^{\circ}\right)$, gives the minimum values of the local head-loss $\Delta \mathrm{E}_{\mathrm{T} 1}$ at the transition from free flow to pipe flow.

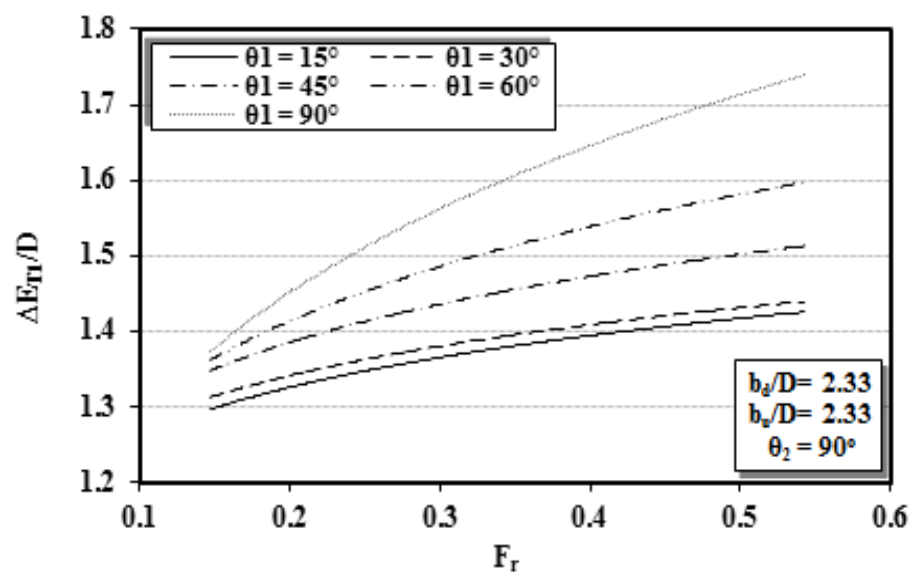

Fig. 7. Relation between of $\Delta E_{T 1} / D$ and $F_{r}$ for different values of $\theta_{1}$ at $h_{d} / D=0.2$

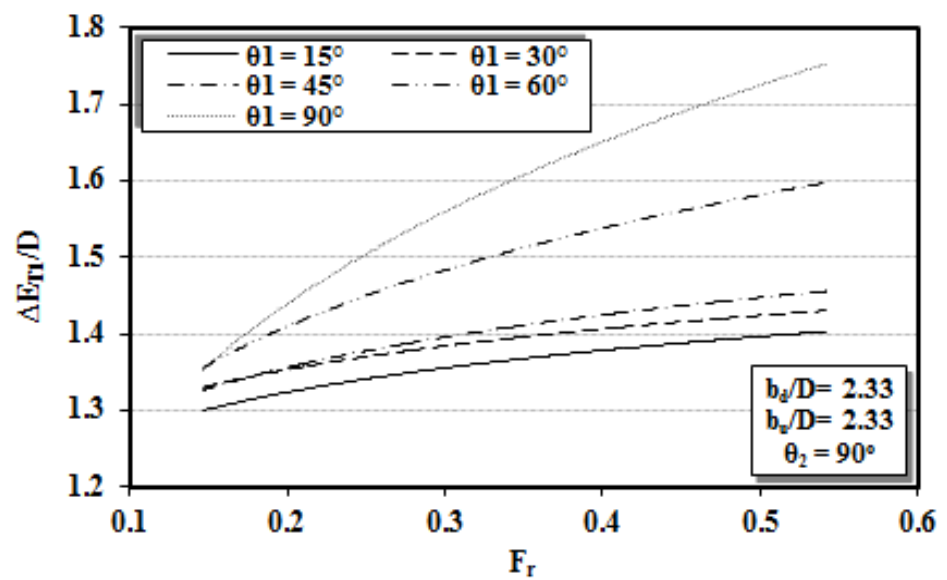

Fig. 8. Relation between $\Delta E_{T 1} / D$ and $F_{r}$ for different values of $\theta_{1}$ at hd/D $=0.4$ 


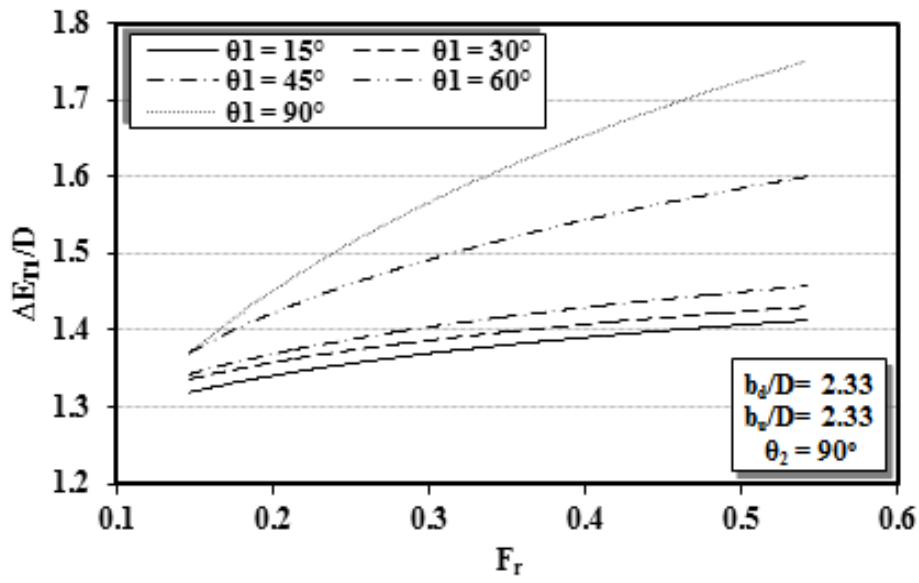

Fig. 9. Relation between $\Delta E_{T 1} / D$ and $F_{r}$ for different values of $\theta_{1}$ at $h d / D=0.6$

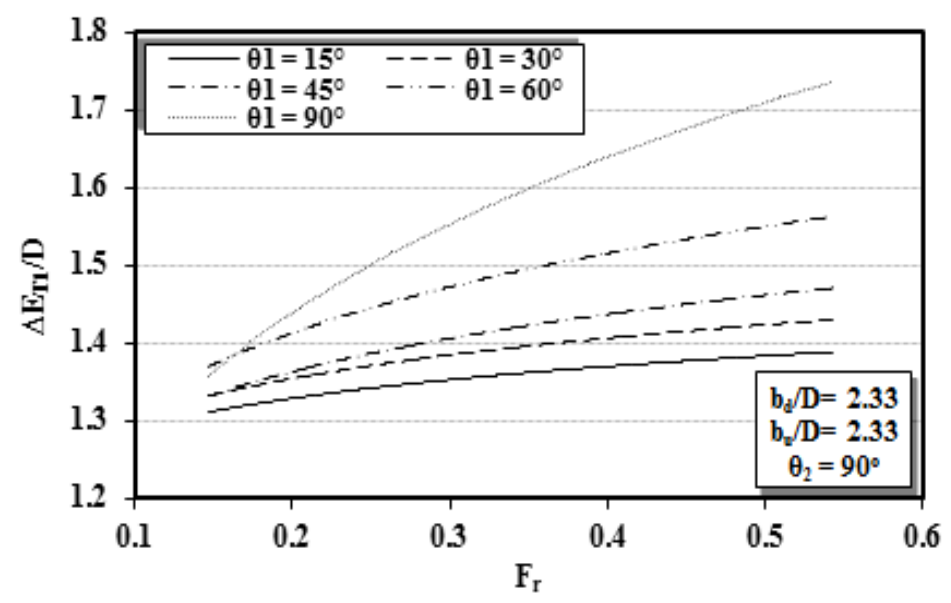

Fig. 10. Relation between $\Delta E_{T 1} / D$ and $F_{r}$ for different values of $\theta_{1}$ at hd/D $=0.8$

\subsection{Effect of downstream contraction ratio $\left(b_{d} / D\right)$ on Local Head-Loss $\left(\Delta E_{T 2}\right)$}

The effect of the downstream contracted width ratios $b_{d} / D$ on relative values of the local head-loss $\Delta \mathrm{E}_{\mathrm{T} 2} / \mathrm{D}$ at the transition from a pipe culvert to a free open channel were presented graphically in Figs. (from 11 to 14) as a function of the tested Froude number, $F_{r}$. for different values of downstream submergence ratio $\left(h_{d} / D\right),\left(\theta_{1}=15^{\circ}\right),\left(\theta_{2}=90^{\circ}\right)$, and upstream contraction ratio $\left(\mathrm{b}_{\mathrm{u}} / \mathrm{D}=2.33\right)$

For all considered downstream submergence ratios $h_{d} / D$ with all tested values of $F_{r}$, the value of $b_{d} / D=2.33$ gives the smaller values of $\Delta \mathrm{E}_{\mathrm{T} 2} / \mathrm{D}$, meaning that, increasing the value of $b_{d} / D$ decreases the value of $\Delta E_{T 2} / D$. Also, for all considered values of $b_{d} / D$ with all tested values of $F_{r}$, increasing the value of downstream submergence ratios $h_{d} / D$ leads to increase the values of $\Delta \mathrm{E}_{\mathrm{T} 2} / \mathrm{D}$ as shown in Figs. (from 11 to 14). Generally, for all considered values of submergence ratio $\left(\mathrm{h}_{\mathrm{d}} / \mathrm{D}\right)$ with all tested values of $\mathrm{F}_{\mathrm{r}}$, using the downstream contraction ratio of 2.33, gives the minimum values of the local head-loss $\Delta \mathrm{E}_{\mathrm{T} 2}$ at the transition from a pipe flow to a free open channel flow. 
Nassralla, T. H., Effect of inlet and outlet geometric shape variations of a pipe culvert on

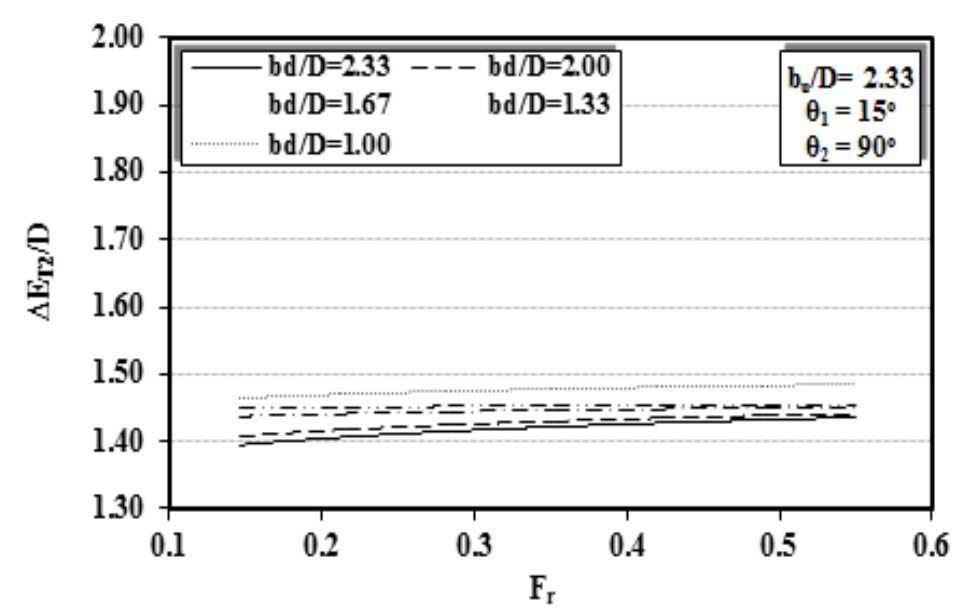

Fig. 11. Relation between $\Delta E_{T 2} / D$ and $F_{r}$ for different values of $\left(b_{d} / D\right)$ at $h_{d} / D=0.2$

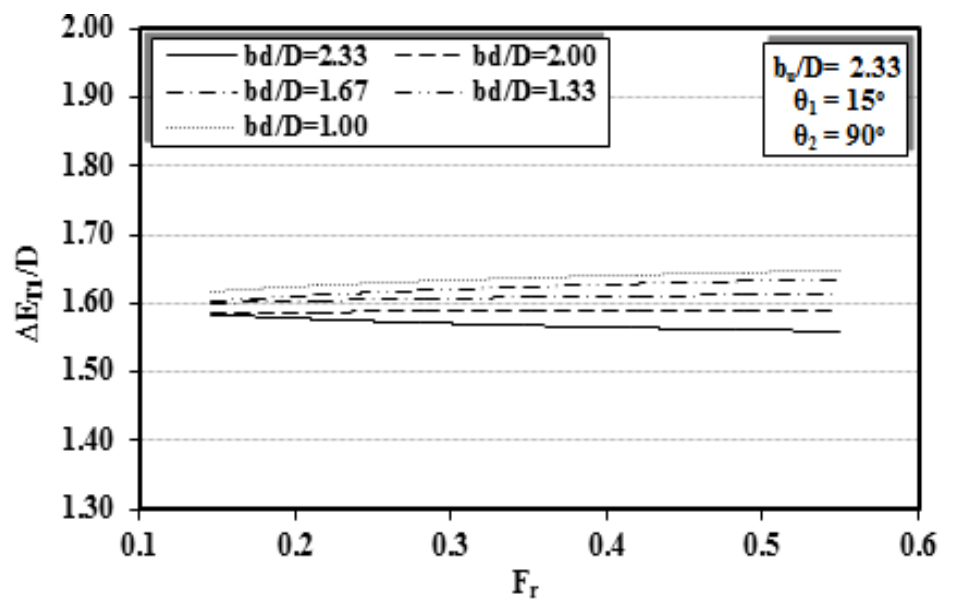

Fig. 12. Relation between $\Delta E_{T 2} / D$ and $F_{r}$ for different values of $b_{d} / D$ at $h_{d} / D=0.4$

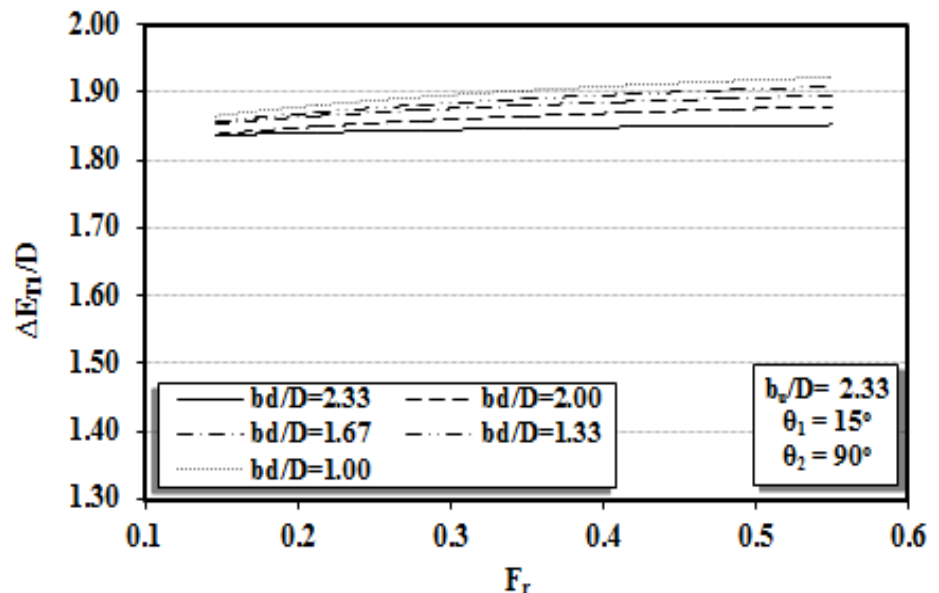

Fig. 13. Relation between $\Delta E_{T 2} / D$ and $F_{r}$ for different values of $b_{d} / D$ at $h_{d} / D=0.6$ 


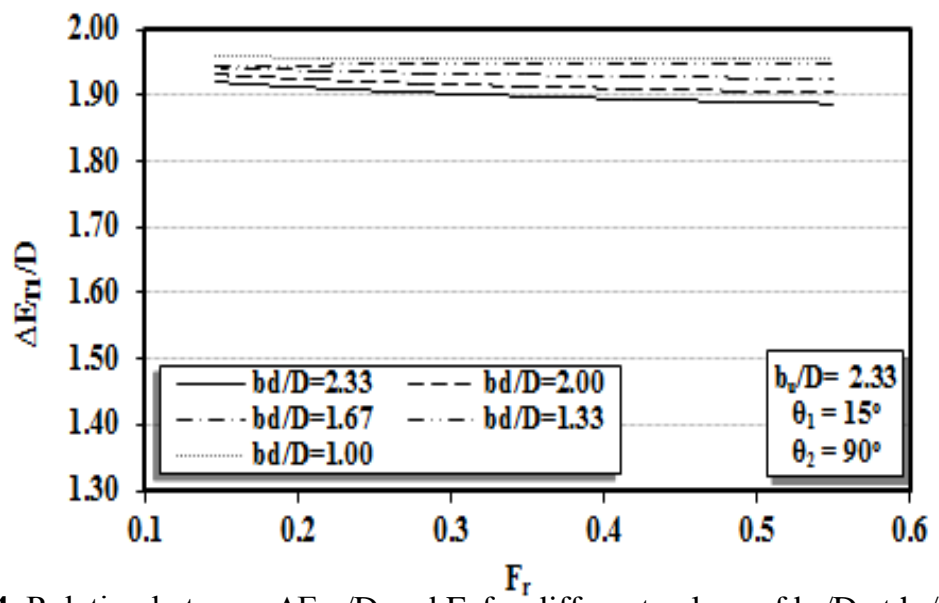

Fig. 14. Relation between $\Delta E_{T 2} / D$ and $F_{r}$ for different values of $b_{d} / D$ at $h_{d} / D=0.8$

\subsection{Effect of downstream angle of sidewall $\left(\theta_{2}\right)$ on Local Head-Loss $\left(\Delta E_{T 2}\right)$}

The relationships were graphically presented to study the effect of the outlet angle of the downstream sidewall $\theta_{2}$ on relative values of the local head-loss $\Delta \mathrm{E}_{\mathrm{T} 2} / \mathrm{D}$ at the transition from pipe flow to free flow as shown in Figs.(from 15 to18) as a function of the tested Froude number, $F_{r}$. for different values of downstream submergence ratio $\left(h_{d} / D\right)$, $\left(\theta_{1}=15^{\circ}\right)$, and $b_{u} / D=b_{d} / D=2.33$.

From these figures, it can be concluded that for submergence ratio of $h_{d} / D=0.2$ with all tested values of $F_{r}$, the value of $\theta_{2}=60^{\circ}$ gives the smaller values of $\Delta E_{T 2} / D$ but for submergence ratios of $\left(h_{d} / D=0.4,0.6\right.$, and 0.8$)$, the value of $\theta_{2}=30^{\circ}$ gives the smallest values while that the value of $\theta_{2}=90^{\circ}$ gives the higher values of $\Delta \mathrm{E}_{\mathrm{T} 2} / \mathrm{D}$ for all values of $\mathrm{h}_{\mathrm{d}} / \mathrm{D}$. These results agree well with the results obtained by Awad M. [16]. Also, it is clear that the $\Delta \mathrm{E}_{\mathrm{T} 2} / \mathrm{D}$ is increased as $\mathrm{F}_{\mathrm{r}}$ increases and for lower values of $\mathrm{F}_{\mathrm{r}}$, all tested values of $\theta_{2}$ had small influence on the values of $\Delta \mathrm{E}_{\mathrm{T} 2} / \mathrm{D}$. Finally, for all considered values of $\theta_{2}$ with all tested values of $F_{r}$, increasing the value of downstream submergence ratios $h_{d} / D$ leads to increase the values of $\Delta \mathrm{E}_{\mathrm{T} 2} / \mathrm{D}$, see Figs.(from 15 to 18). Generally, at a specific value of Froude number $F_{r}$ the outlet angle $\theta_{2}=60^{\circ}$ gives the minimum value of $\Delta \mathrm{E}_{\mathrm{T} 2} / \mathrm{D}$, these results match at $\left(\mathrm{h}_{\mathrm{d}} / \mathrm{D}=0.2\right)$. But with the increase of downstream submerged ratios of $\left(\mathrm{h}_{\mathrm{d}} / \mathrm{D}=0.4,0.6\right.$ and 0.8$)$, the outlet angle of $\theta_{2}=30^{\circ}$ give the minimum values of $\Delta \mathrm{E}_{\mathrm{T} 2} / \mathrm{D}$.

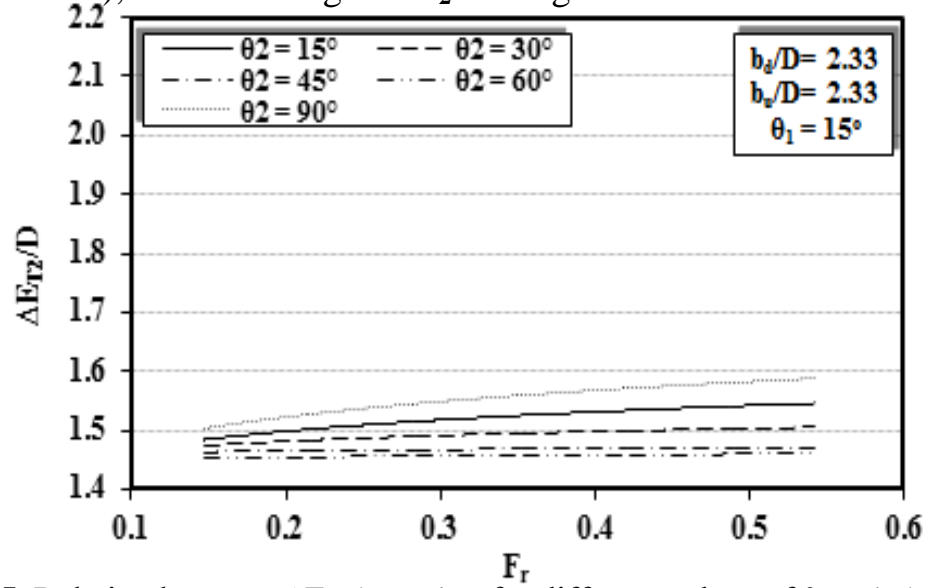

Fig. 15. Relation between $\Delta E_{T 2} / D$ and $F_{r}$ for different values of $\theta_{2}$ at $h_{d} / D=0.2$ 
Nassralla, T. H., Effect of inlet and outlet geometric shape variations of a pipe culvert on

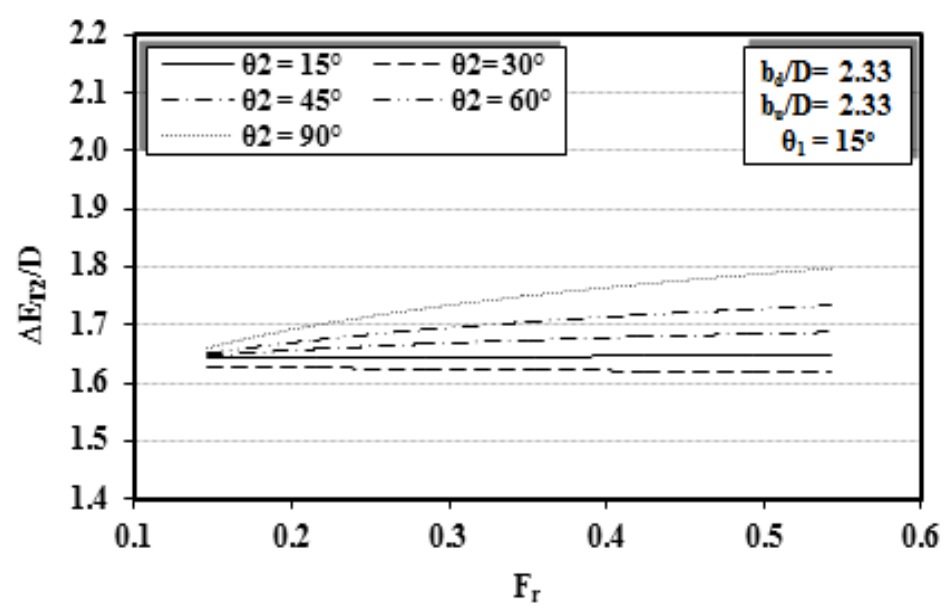

Fig. 16. Relation between $\Delta E_{T 2} / D$ and $F_{r}$ for different values of $\theta_{2}$ at $h_{d} / D=0.4$

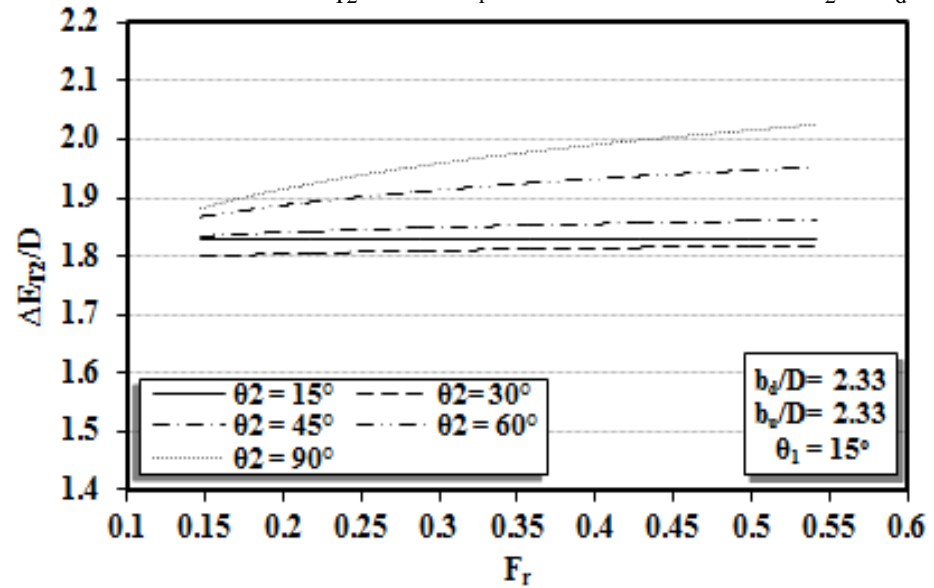

Fig. 17. Relation between $\Delta E_{T 2} / D$ and $F_{r}$ for different values of $\theta_{2}$ at $h_{d} / D=0.6$

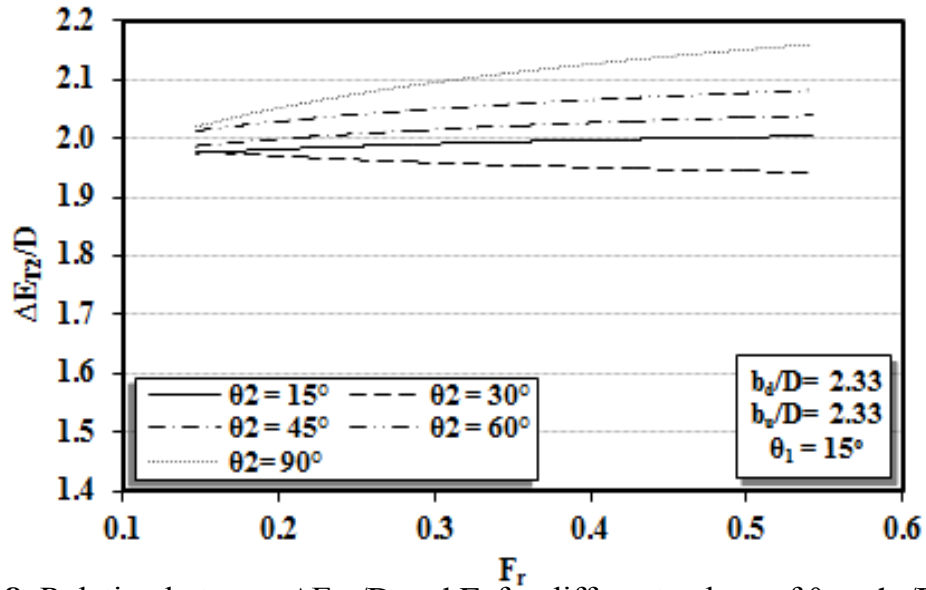

Fig. 18. Relation between $\Delta E_{T 2} / D$ and $F_{r}$ for different values of $\theta_{2}$ at $h_{d} / D=0.8$

\section{Local Head-Loss coefficient}

The calculated friction coefficient in the free-surface channel is very small. So, the local 
head-loss coefficient $\mathrm{k}$ at the transition may be computed as a function of the flow kinetic energy as follow:

$$
k=\frac{2 g \Delta E_{T}}{V^{2}}
$$

The reference velocity $\mathrm{V}$ can be selected so that no problem arises for its determination in further applications. Throughout this study, the values of the reference velocity $\mathrm{V}$ are referred to the Cross Section 3, computed from Eq. 4, whatever the discharge and geometrical configurations are, as the downstream boundary condition has been regulated to always create pressurized flow along the whole culvert length, Nguyen et al. [15].

The entrance local head-loss coefficient $\left(\mathrm{k}_{\mathrm{u}}\right)$ was calculated as a function of the ratio of the downstream cross section area, $A_{3}$ to the upstream one $A_{1}$, (Sections 3 and 1 , respectively in Fig. 2) as follow:

$$
k_{u}=a\left(1-A_{3} / A_{1}\right)
$$

The downstream local head-loss coefficient $\mathrm{k}_{\mathrm{d}}$ was calculated as

$$
k_{d}=b\left(1-A_{3} / A_{5}\right)
$$

Where, $A_{3} / A_{5}$ is ratio of the cross section area $A_{3}$ to the downstream one $A_{5}$, (Sections 3 and 5, respectively in Fig. 2), $\mathrm{a}$ and $\mathrm{b}$ are coefficients that should be determined experimentally.

Based on the experimental results, the coefficient a, was found between 0.426 and 1.213 and the coefficient $b$, was found between 0.322 and 0.976 . These experimental results are in close agreement with the findings by Tullis et al. [13].

\subsection{Derivation of Local Head-Loss}

It is important to predict local head loss at the transition from open channel flow to pipe flow $\Delta \mathrm{E}_{\mathrm{T} 1}$, and local head loss at the transition from pipe flow to open channel flow $\Delta \mathrm{E}_{\mathrm{T} 2}$ for the different cases being under investigation. Based on the experimental data and using the statistical methods with the presence of the different flow conditions, several models were proposed and their coefficients were estimated. The best equations predicting $\Delta \mathrm{E}_{\mathrm{T} 1}$ and $\Delta \mathrm{E}_{\mathrm{T} 2}$ may be as:

$$
\begin{aligned}
\frac{\Delta E_{T 1}}{D} & =1.32 F_{r}^{0.18}\left(\frac{h_{d}}{D}\right)^{-0.005}\left(\theta_{1}\right)^{0.098}\left(\frac{b_{u}}{D}\right)^{-0.08} \\
\frac{\Delta E_{T 2}}{D} & =2.17 F_{r}^{0.013}\left(\frac{h_{d}}{D}\right)^{0.224}\left(\theta_{2}\right)^{-0.007}\left(\frac{b_{d}}{D}\right)^{-0.006}
\end{aligned}
$$

Figure (19) shows a comparison between the measured relative local head loss at the transition from open channel flow to pipe flow, $\left(\Delta \mathrm{E}_{\mathrm{T} 1} / \mathrm{D}\right)$ and the calculated one using Eq. 13. Figure (20) compares the measured relative local head loss at the transition from pipe flow to open channel flow, $\left(\left(\Delta \mathrm{E}_{\mathrm{T} 2} / \mathrm{D}\right)\right.$ and the calculated one using Eq. 14. It can be noticed that, the predicted data agrees well with the measured one. The developed model of the equation has been validated through the tested condition. The regression statistics for Eqs. 13 and 14 define the coefficients of determination $\left(\mathrm{R}^{2}\right)$ as 0.86 and 0.92 respectively. 
Nassralla, T. H., Effect of inlet and outlet geometric shape variations of a pipe culvert on ..........

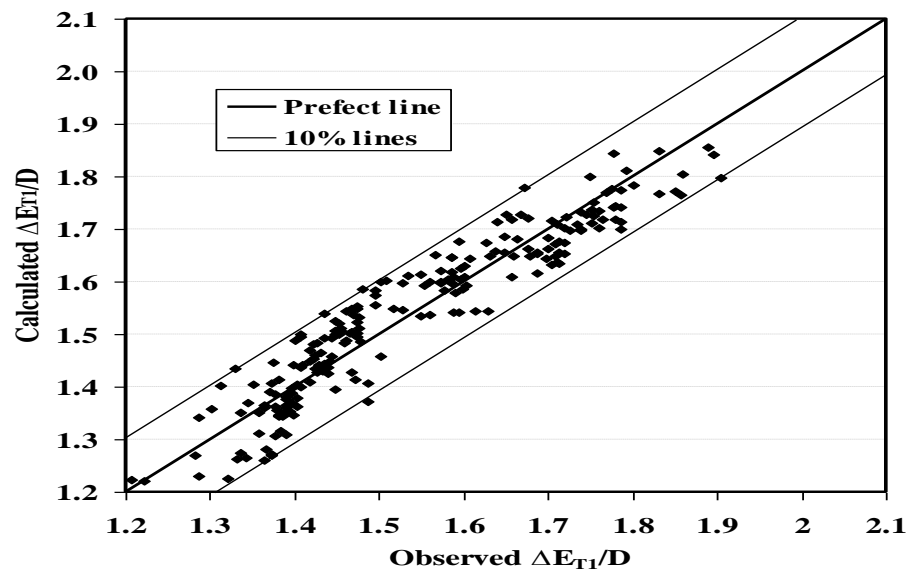

Fig. 19. Comparison between calculated and measured values of $\Delta \mathrm{E}_{\mathrm{T} 1} / \mathrm{D}$

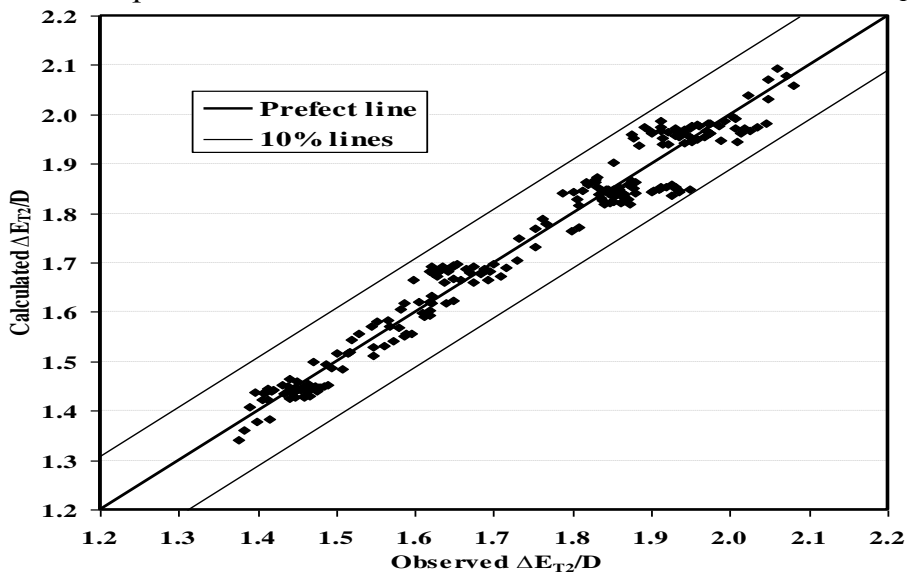

Fig. 20. Comparison between calculated and measured values of $\Delta E_{T 2} / D$

\section{Conclusions}

The conclusions from this study may be as:

- The values of $b_{u} / D=2.33$ and $b_{d} / D=2.33$ give the lower values of $\Delta E_{T 1} / D$ and $\Delta \mathrm{E}_{\mathrm{T} 2} / \mathrm{D}$ respectively.

- The value of $\theta_{1}=15^{\circ}$ gives the smaller values of $\Delta \mathrm{E}_{\mathrm{T} 1} / \mathrm{D}$ while the value of $\theta_{1}=90^{\circ}$ gives the higher values of $\Delta \mathrm{E}_{\mathrm{T} 1} / \mathrm{D}$.

- For lower values of $F_{r}$, the angle of sidewalls and the value of contraction ratios at the inlet and outlet of the pipe culvert had small effect on the values of Local Head-Losses.

- With all tested values of $F_{r}$ and all tested values of submergence ratio of $h_{d} / D$, the value of $\theta_{2}=90^{\circ}$ gives the higher values of $\Delta \mathrm{E}_{\mathrm{T} 2} / \mathrm{D}$. But the value of $\theta_{2}=60^{\circ}$ for submergence ratios of $\left(h_{d} / D=0.2\right)$ and the value of $\theta_{2}=30^{\circ}$ for submergence ratios of $\left(h_{d} / D=0.4,0.6\right.$, and 0.8$)$ give the smaller values of $\Delta E_{T 2} / D$

- Increasing the value of downstream submergence ratios $h_{d} / D$ leads to increase the values of $\Delta \mathrm{E}_{\mathrm{T} 2} / \mathrm{D}$. But it had small effect on the values of $\Delta \mathrm{E}_{\mathrm{T} 1} / \mathrm{D}$. 
Upstream and downstream local head-loss coefficients were determined for the tested geometrical configurations. Equations predicting the local head loss at the transition from open channel flow to pipe flow and the local head loss at the transition from pipe flow to open channel flow are presented with limitation to tested conditions.

\section{Acknowledgments}

This work was carried out at the Hydraulics Research Institute (HRI), National Water Research Center (NWRC) in Egypt. The author gratefully acknowledges the collaboration done by all staff members of the Institute during the experimental work.

\section{NOTATION}

The following symbols were used through this research:

A is wetted area of cross section $\left(\mathrm{m}^{2}\right)$;

$\mathrm{B}$ is upstream and downstream open channel width $(\mathrm{m})$;

$b_{d}$ is width of contracted open section at downstream $\left(b_{d}=B-2 b_{w}\right),(m)$;

$b_{i}$ is bed width at cross section $i$ of the free-surface channel $(\mathrm{m})$;

$b_{u}$ is width of contracted open section at upstream sidewall $\left(b_{u}=B-2 b_{w}\right),(m)$;

$b_{w}$ is width of upstream or downstream sidewall (width of abutment) (m);

$\mathrm{D}$ is diameter of the pipe culvert $(\mathrm{m})$;

$\mathrm{D}_{\mathrm{h}}$ is hydraulic diameter $(\mathrm{m})$;

$\Delta E_{l-3}$ is energy difference from section 1 to $3(\mathrm{~m})$;

$\Delta E_{3-5}$ is energy difference from section 3 to $5(\mathrm{~m})$;

$\Delta \mathrm{E}_{\mathrm{j}}$ is friction loss in the free-surface channel/pipe reach $(\mathrm{m})$;

$\Delta \mathrm{E}_{\mathrm{T} 1}$ is local head loss at the transition from open channel flow to pipe flow (m);

$\Delta \mathrm{E}_{\mathrm{T} 2}$ is local head loss at the transition from pipe flow to open channel flow (m);

$\mathrm{F}_{\mathrm{r}}$ is the Pipe Froude number (-);

$f$ is friction factor (-);

$\mathrm{g}$ is gravitational acceleration $\left(\mathrm{m} / \mathrm{s}^{2}\right)$;

$h_{d}$ is submerged depth above the pipe culvert at downstream side of the culvert (m);

$\mathrm{h}_{\mathrm{i}}$ is water depth at cross section $\mathrm{i}$ of the free-surface channel (m);

$\mathrm{L}$ is pipe culvert length (m);

$\mathrm{L}_{\mathrm{d}}$ is length of the sidewalls at downstream side of the culvert (m);

$\mathrm{L}_{\mathrm{u}}$ is length of the sidewalls at upstream side of the culvert (m);

$\mathrm{k}$ is local head-loss coefficient (-);

$\mathrm{p} / \gamma$ is pressure head at cross section 3 of the pipe culvert $(\mathrm{m})$;

$\mathrm{S}$ is bed slope in the free-surface channel/conduit reach $(\mathrm{m} / \mathrm{m})$;

$\mathrm{V}_{\mathrm{i}}$ is mean flow velocity at cross section $\mathrm{i}(\mathrm{m} / \mathrm{s})$;

$\mathrm{x}$ is reach length $(\mathrm{m})$;

$\theta_{1}$ is inlet angle of the upstream sidewall at upstream side of the pipe culvert;

$\theta_{2}$ is outlet angle of downstream sidewall at downstream side of the pipe culvert;

$\mu$ is dynamic viscosity of water (N.s. $/ \mathrm{m}^{2}$ ).

$\rho$ is density of the water $\left(\mathrm{kg} / \mathrm{m}^{3}\right)$; and

\section{REFERENCES}

[1] Chow, V. T., (1959). Open Channel Hydraulic, McGraw-Hill, book company, Chapter 17, PP. 493-498.

[2] Blaisdell, F.W. (1960). "Hood Inlet for Closed Conduit Spillways", Journal of Hydraulic Division, ASCE, Vol. 86, No.5, PP.7-31.

[3] Gardel, A. (1962). Perte de charge dans un étranglement conique, Editions de la Société du Bulletin Technique de la Suisse Romande, Lausanne, 
Nassralla, T. H., Effect of inlet and outlet geometric shape variations of a pipe culvert on ..........

[4] Bodhain, G. L. (1982). Measurement of Peak Discharge at Culvert by Indirect Method, Section A3, Book 3. U.S., Geological Survey, Government Printing Office, Washington D.C.

[5] Idel'cik, I. E. (1986). Handbook of hydraulic resistance, Hemisphere Publishing, Washington, DC.

[6] Dasika, B. (1995). New Approach to Design of Culvert, J. Irrig. Drain. Eng., ASCE, Vol. 121, No.3, PP. 261-264.

[7] Montes, J. S. (1997). Discussion of New Approach to Design of Culverts, Journal of Irrigation and Drainage Engineering, ASCE, Vol. 123, No. 1, PP. 71-72.

[8] Montes J.S. (1997). Irrotational flow and real fluid effects under planar sluice gates. J. Hydraul. Eng., 1997; 123(3), 219-232.

[9] Hager, W. H. and Giudice, G.D. (1998).Generalized Culvert Design Diagram, Journal of Irrigation and Drainage Engineering, Vol. 124, No. 5, PP. 271-274.

[10] Norman, J. M., Houghtalen, R. J., and Johnston, W. J. (2001). Hydraulic design of highway culverts, Hydraulic Design Series No. 5 (HDS-5), Rep. FHWA-NHI-01-020, U.S.

[11] Meselhe, E. and Hebert, K. (2007). Laboratory Measurements of Flow through Culvert, Jaurnal of Hydraulic Engineering 133, No.8, PP. 973-976.

[12] Hager, W. H. (2008). Wastewater hydraulics: Theory and practice, Springer, New York.

[13] Tullis, B. P., Anderson, A. S., and Robinson, S. C. (2008). Entrance loss coefficients and inlet control head-discharge relationships for buried invert culverts.” J. Irrig. Drain. Eng., 134(6), 831-839.

[14] McGovern, J. (2011). Friction factor diagrams for pipe flow, Dublin Institute of Technology, Dublin, Ireland, 15.

[15] Nguyen V N, Pierre A, Benjamin D, Michel P, and Sébastien E, (2013). Local Head-Loss Coefficient at the Rectangular Transition from a Free-Surface Channel to a Conduit, J. Hydraul. Eng. ASCE, 2013.139(12):1318-1323.

[16] Awad M.AM. (2014). "Optimum design of the inlets and outlets of syphons", Phd. Water Engineering, Faculty of Engineering, Zagazig University.

[17] Gisonni, C. and Pfister, M. (2015). Head losses in sewer junction. E-proceedings of the 36th IAHR World Congress 28 June - 3 July, 2015, The Hague, the Netherlands. 


\section{تأثير التغيرات الهنسيه لمدخل ومخرج ماسورة بريخ على الفواقد الهيلروليكية المحلية 822 المالية}

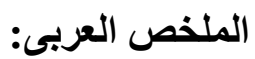

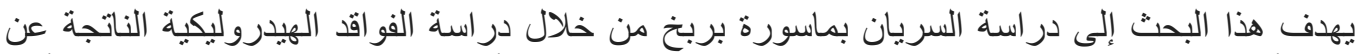

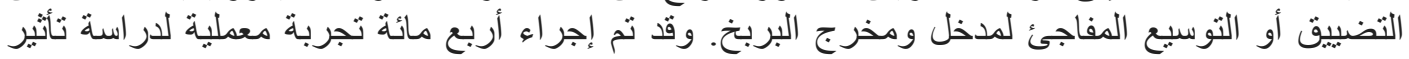

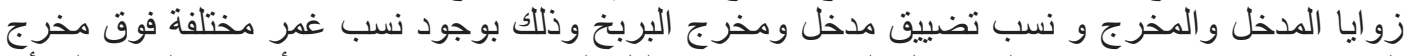

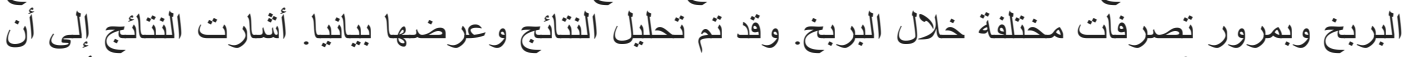

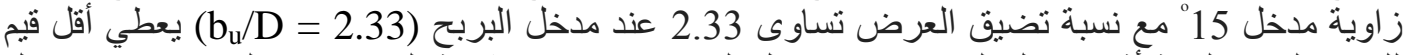

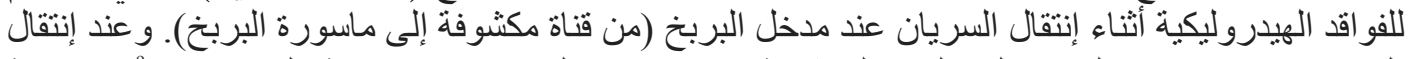

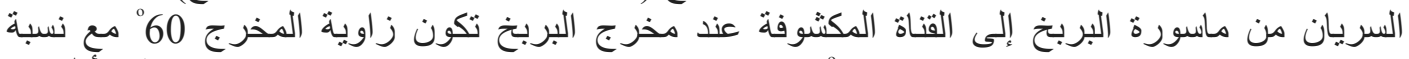

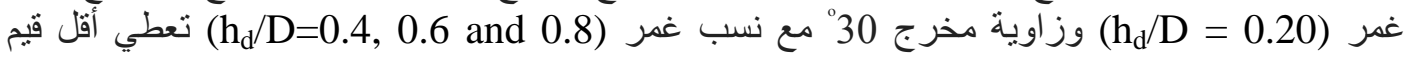

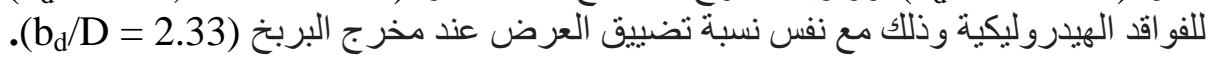

